Such instances could be multiplied, and the fact is that, for all its length, The Nature of the Book lacks not only definitiveness, but also balance: throughout its 750 pages it is arguing a case rather than saying the final word even on scientific publishing in seventeenth-century England.

Yet Johns's decision to write a big book rather than a smaller one may be germane to the very issues that dominate the work itself, namely the extent to which people's approach to the printed word is affected by factors extrinsic to a book's actual content. People defer to long books, and Johns may well be correct in thinking that a weighty tome like this will gain an authority for his iconoclastic view of print that would not have been the case with a work half the length. Yet, if he is right in this, it is to be hoped that he will not be a victim of his own success: readers should not be discouraged by the sheer length of the book from sampling some of the lively and insightful sections that make it up.

Michael Hunter is in the Department of History,

Birkbeck College, University of London, London WC1 7HX, UK.

\section{Roaming the landscape}

\section{Fractal River Basins: Chance and Self-Organization}

by Ignacio Rodríguez-Iturbe and Andrea Rinaldo

Cambridge University Press: 1997. 547 pp.

$£ 70, \$ 100$

\section{David R. Montgomery}

The search for meaning in the branching patterns of channel networks has seduced geomorphologists for decades, and Fractal River Basins makes a compelling case for a fundamental order in landscape form. Ignacio Rodríguez-Iturbe and Andrea Rinaldo provide a benchmark synthesis and passionate exploration of the ways in which fractal geometry can be used to analyse river networks, and how the concepts of optimal channel networks (OCNs) and self-organized criticality (SOC) can be applied to models of landscape evolution. In a rigorous and engaging style, they explore the themes of necessity and chance in river-basin evolution to develop the argument that fractal geometry contributes more to geomorphology than just a convenient shorthand for the thumbprint of river incision.

Fractal River Basins goes beyond the descriptive application of fractals to examine the universal aspects of landscape development. An excellent overview of river-basin morphology opens the book and leads into a discussion of the use of fractals to describe the wide variety of scale-free aspects of river networks and river-basin morphology.

The authors delve into examples where fractal descriptions and models are supported by observations from real networks, but they also discuss how channel networks are not simple, self-affined monofractals, and emphasize that planform models of network structure are not demanding when it comes to statistical tests of their veracity. A wide variety of models produce arborescent patterns that resemble natural channel networks, and the robust generality of the fractal aspects of channel networks has led many geomorphologists to question the utility of fractals for elucidating the processes of network growth and landscape evolution.

Rodríguez-Iturbe and Rinaldo argue that models of landscape evolution should be assessed by examining the three-dimensional structure of basins (that is, including elevation), and they propose that OCNs provide a bridge between fractal patterns and landscape-forming processes. In a discussion that summarizes a decade of cutting-edge research, they start from the premiss that channel networks are characterized by minimum rates of energy expenditure to show that the connectivity and elevation structure of OCNs resembles that of natural drainage basins.

They argue that both chance and necessity govern river-basin evolution - chance through the effect of random variations in initial conditions and necessity through minimization of the total rate of energy expenditure both for the whole network and locally throughout a river network. In drawing previous work together into a single chapter the authors provide a very welcome and valuable synthesis of a wide range of studies on OCNs and a comprehensive case for their relevance to river-basin evolution.

The authors' examination of how the structure of river basins is formed bySOC contrasts with a perception among some process geomorphologists that SOC offers little to those seeking to understand land-form. It is not too surprising, therefore, that in framing their discussion oflandscape self-organization and river-basin evolution, Rodríguez-Iturbe and Rinaldo decry the "reductionist, processoriented tenet to which most geomorphology is committed". But both reductionism and the synthetic examination of emergent properties are necessary tools for the well-rounded geomorphologist, given that process geomorphology in general seeks to understand how and to what degree the processes driving landscape evolution translate across a wide range of scales.

Moreover, some process-based understanding is necessary to evaluate the implications of the principle of minimum energy dissipation; without a tie to landscapeforming processes, the existence of broad, ubiquitous, self-similar characteristics of landscapes teaches us little about how particular landscapes evolve. Even though a fundamental tension underlies the search for universal and landscape-specific aspects of land-form, there is value in searching for insight in both the ubiquitous and the discriminating characteristics of landscapes.

However one looks at the subject, Fractal River Basins is an important book that explores the fundamental dynamics behind the generally uniform appearance of river networks and fluvially sculpted landscapes. The reader seeking an exploration of the relevance of fractal geometry to the description of river networks will be rewarded with a stateof-the-art review.

The seductive beauty of channel networks will continue to inspire investigators to examine the deep symmetry expressed in landscape form, and Fractal River Basins provides a bold synthesis of probability, physics and geometry that will stand as a definitive work on a complex subject. Geomorphologists and physicists alike will find the book thought-provoking, and I highly recommend this stimulating work as a means of focusing one's thinking on the role of fractals, OCNs and SOC in fluvial geomorphology and landscape evolution.

David R. Montgomery is in the Department of Geological Sciences, University of Washington, Seattle, Washington 98195-1310, USA.

\title{
The splendour of Yellowstone
}

This aerial view of Sour Creek, showing the mosaic of meandering streams, ponds and wetlands across open pasture, is one of many photographs taken by Norbert Rosing for Yellowstone (Firefly, \$24.95), in which the photographer aims to convey the fascination of Yellowstone National Park, with its enduring geological monuments, geysers, plants and wildlife.

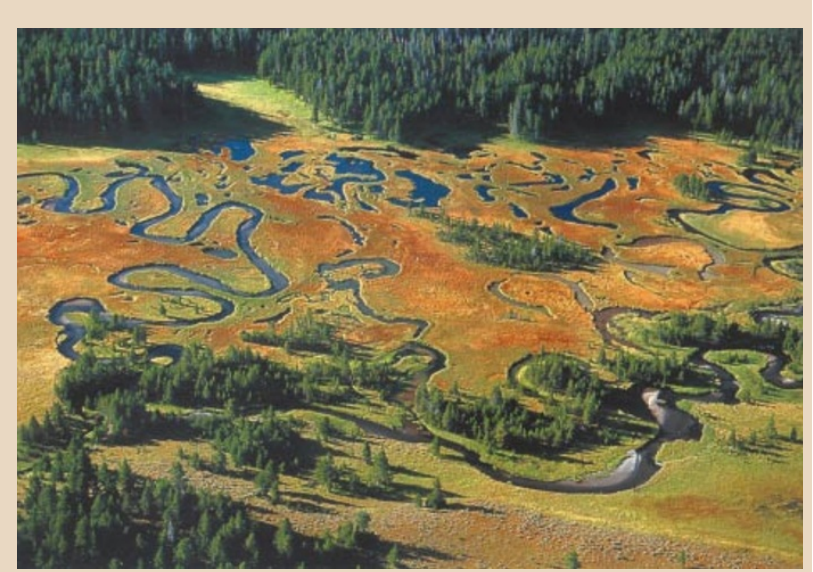

